\title{
Mathematical Discussion on the Relationship Between SUTs and SIOTs
}

\author{
Trinh Bui ${ }^{1} \&$ Ngoc Quang Pham ${ }^{2}$ \\ ${ }^{1}$ Association of Regional Econometrics and Environmental Studies (AREES), Vietnam \\ ${ }^{2}$ FPT School of Business and Technology (FSB), FPT University, Vietnam \\ Correspondence: Ngoc Quang Pham, FPT School of Business and Technology (FSB), FPT University, Block C, \\ VAS-FSB Building, My Dinh 1, Nam Tu Liem, Hanoi, Vietnam. Tel: 84-90-433-1656.
}

Received: February 22, 2021

Accepted: April 7, 2021

Online Published: May 12, 2021

doi:10.5430/rwe.v12n3p53

URL: https://doi.org/10.5430/rwe.v12n3p53

\begin{abstract}
Since the 1993 System of National Accounts (SNA) and especially the 2008 SNA, traditional input-output table (IOT) of Leontief has been modified quite a lot with many variations. The supply and use tables (SUTs) seem to be substituted for the IOT, although there has not been a complete guiding to SUTs to IOT conversion.

Originally in 1968 SNA, SUTs was called make and use matrices as an intermediate step to compile IOT. However, 1993 and 2008 SNA seem to replace IOT with SUTs, of which regulations make it difficult to convert from SUTs to IOT such as regulation on the size of supply and use tables and regulation on the prices of the intermediate input matrix.

Some countries use computable general equilibrium (CGE) model, while others use both the CGE model and input-output analysis, so they need to convert SUTs into symmetric input-output tables (SIOTs). The construction of SIOTs is a controversial issue as regards the choice of model to construct both product-by-product and industry-by-industry SIOTs. This paper discusses the SUTs given in 1968, 1993, 2008 SNA, and the method for converting SUTs to SIOTs.

Although there have been several articles on how to convert SUTs into SIOTs, this article is an effort to provide an easier, more understandable way to convert SUTs to SIOTs based on the arrangement of supply and use matrices.
\end{abstract}

Keywords: input, industry, output, product, supply, use

\section{Introduction}

The concept of the make and use matrices first appeared in 1968 SNA. The make and use matrices were used as the intermediate step for compiling the input-output table (IOT). Until 1993 SNA, the make and use matrices were called supply and use tables (SUTs), since then the term IOT is faint. There are two basic directions in applying the SUTs and IOT: computable general equilibrium (CGE) model and input-output analysis in economic analysis.

The main difference between SUTs and IOT is classification of products and industries. When the input-output matrix of technical coefficients (the A matrix) is [\# of product by \# of product] or [\# of industry by \# of industry], the supply and use coefficient matrices present industries across columns and products across rows.

In 1968 SNA, the United Nations introduced the make and use matrices in the compilation of IOT (United Nations, 1968). In the 1993 revision (United Nations, 1999) and 2008 revision (United Nations, 2009), the make and use matrices were called supply and use tables. In these versions, prices of output vector were mentioned and the supply and use tables were not necessarily a square matrix. These can lead to difficulties for those who use the input-output system for analysis. In most discussions of converting SUTs to IOT, attention has focused on two assumptions, commodity technology and industry technology (Jansen \& ten Raa, 1990; Bui, Kobayashi, \& Kim, 2012; Bui, 2016). Moreover, 1993 SNA and 2008 SNA raised another issue that supply matrix of supply table must be at basic prices, and intermediate input matrix of the use table must be at purchasers' prices. These prompt a question: what would be a problem when converting SUTs to IOT while (1) the supply and use matrices are non-square and (2) the price basis of these tables is different.

Soklis (2009) has reviewed some available methods used to convert SUTs to IOT. He argues that all conversion methods rest on an unrealistic assumption that single production, not joint production, characterizes economic structure of real world. To improve upon this unrealistic assumption, various methods of IOT compilation introduce 
technical treatments for relaxation of this assumption. Bui el al. (2012) proposes a method for arranging supply and use matrices as sub-matrix in interregional analysis. This approach applied for compiling Vietnam IOT 2007 and the updated Vietnam IOT 2016. The U.S. Bureau of Economic Analysis (BEA) uses mixed or hybrid technology assumptions to create symmetric input-output tables (SIOTs) (Guo, Lawson, \& Planting, 2002). This method involves a two-step process, in which some secondary products are first redefined or modeled by hand to the industries where they are primarily based on the principle of homogeneity of the input structures of the commodities. This step is of treatment, which is called the redefinition method.

To make the transition from SUTs to IOT easier for countries that use both input-output analysis and CGE model, this paper proposes an applied matrix approach for creating a linkage between SUTs and SIOTs after balancing the SUTs. The paper is organized as below: section (2) presents the supply and use tables used for the compilation, section (3) proposes a method for compilation of SIOTs from SUTs, section (4) presents results of empirical study, and section (5) concludes.

\section{Supply and Use Tables for the Compilation of SIOTs From SUTs}

\subsection{Background}

IOT is the representative statistic framework, which captures the revolving structure of the national economy based on "product by product" or "industry by industry" structure. IOT is an integral part of the System of National Account, which aims to record not only transaction structure of goods and services but also production technology (the $A$ matrix) at the same time.

The $A$ matrix generally depicts either the direct requirements of "commodity $i$ " needed to produce a physical unit of "commodity $j$ ", or the direct inputs from "industry $i$ " needed to produce one physical unit of "industry $j$ ". The former is built up with product-by-product IOT and the later, with industry-by-industry IOT.

The observation of an input-output survey is an establishment, which is defined as a business unit engaged in one business activity in a single location. In the case of multi-activity business units, their activities are broken down into establishments according to their engaging activities.

When an establishment produces commodities that are not its principal product, these activities are classified either as secondary or as ancillary: (1) a secondary activity is an activity carried out within a single establishment in addition to the principal activity; (2) an ancillary activity is a supporting activity, which is undertaken to create the conditions in which the activities of an establishment can be carried out. The value of products of ancillary activities is normally small as compared with that of the principal product since they are treated as an integral part of activities - in which they are associated.

Three issues are emerging here. First, products and industries cannot always be classified in the same way. Second, in addition to a multitude of inputs, industries may also have a multitude of outputs. Third, products contained in each row and column of an industry-by-industry table are not homogeneous in terms of production. Hence, the make and use system replaces "Leontief IO model" with two matrices, which are make matrix of outputs and use matrix of inputs under the 1968 SNA's recommendation.

Under the 1993 SNA and 2008 SNA revisions, SUTs are in the form of matrices that record how supplies of different kinds of goods and services are originated from domestic industries and imports, and how those supplies are allocated between various intermediate or final uses, including exports. SUTs provide a detailed description of transactions with goods and services realized in the year. They show resources (outputs, imports, net taxes on products) and uses (intermediate consumption, final consumption, gross capital formation, and exports) of goods and services.

The basic construction of SUTs is a matrix [\# of product by \# of industry], which allows analyzing the production of industries and resources of commodities on the one side, and intermediate consumption and final use on the other side. Moreover, there is an income approach to gross domestic product below the intermediate consumption matrix. The construction of SUTs is based on the two equations as follows:

Total output by industry = Total input by industry (sum of intermediate consumption and value added)

$$
\text { Supply by products }=\text { Use by products }
$$

This new framework provides a more accurate description of product flows and at the same time brings attention to a new problem in the construction of technical coefficients. The construction of technical coefficients was reduced to a matter of treatment of secondary products. Many establishments produce only one group of commodities. However, some establishments produce commodities that are not among the primary product of the industry to which they are 
belonging. As a result, non-zero off-diagonal elements would appear in the make matrix. The alternative treatment of secondary products rests upon the separation of outputs and inputs of the industry in which the secondary product is a characteristic output. Assumptions on these input structures imply $A$ matrix of technical coefficients as a function of the make and use matrices.

The make matrix and the use matrix were presented in the 1968 System of National Accounts (SNA) as an initial and intermediate step for compiling IOT. The General Statistics Office of Vietnam compiled the IOTs based on this rule. When the 1993 SNA revision was established, the make and use matrices were converted into the SUTs, and for such reasons, IOT seems to be disappeared in the 1993 SNA revision.

\subsection{Supply Table}

Figure 2 illustrates the layout of the Supply Table at basic prices. The supply matrix $S$ [\# of product by \# of industry] shows the domestic production of goods and services at basic prices. The supply matrix $S$ is merely the transposition of the make matrix $V$ [\# of industry by \# of product]. The rows of the supply matrix show the products (goods and services) produced by the respective industries; the columns show the different activities (industries). We have:

$$
\begin{aligned}
& \mathrm{I}_{1} * \mathrm{~S}=\mathrm{g}^{\mathrm{T}} \\
& \mathrm{S} * \mathrm{I}_{2}=\mathrm{q}
\end{aligned}
$$

where:

$g \quad$ column vector of industry output at basic price [\# of industry]

$q$ column vector of product output at producer price [\# of product]

$\mathrm{T}$ transposition symbol

$I_{1} \quad$ identify row vector [\# of product]

$I_{2} \quad$ identify column vector [\# of industry].

It is noted that in this Supply Table column vectors of trade margin, transportation margin and net taxes on products become irrelevant as they were deducted from the use table at purchasers' prices. Import column is also absent as imports are shown in the Use Table.

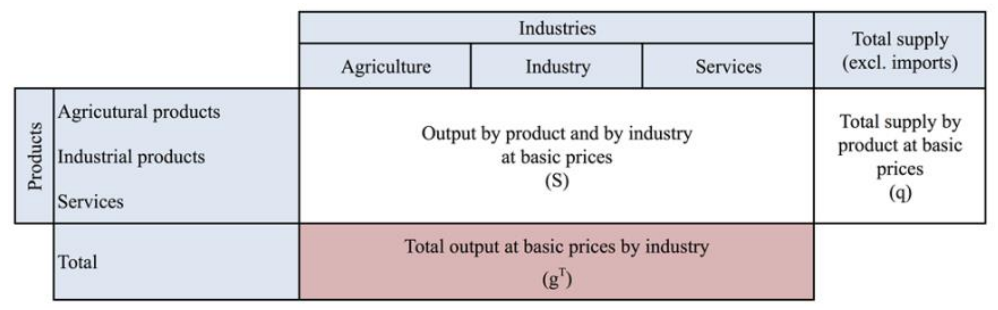

Figure 1. Layout of the supply table

Source: Authors' adaptation from Eurostat (2008)

\subsection{Use Table}

Figure 2 illustrates the layout of the Use Table, which consists of the intermediate consumption matrices at basic prices, taxes less subsidies on products, the value-added matrix at basic prices, and the final use matrix. The use matrix $U$ shows domestic intermediate input by column and domestic intermediate demand by row. Imports are described by two separated matrices, namely imports for intermediate consumption $M_{1}$ [\# of product by \# of industry] and imports for final uses $M_{2}$ [\# of product by \# of final use category]. The value-added matrix $W$ shows factors of value added by component (row) and by industry (column). The components of value-added include: (1) Compensation of employees, (2) Tax on production plus subsidies (excludes tax on products), (3) Depreciation, and (4) Operating surplus. 


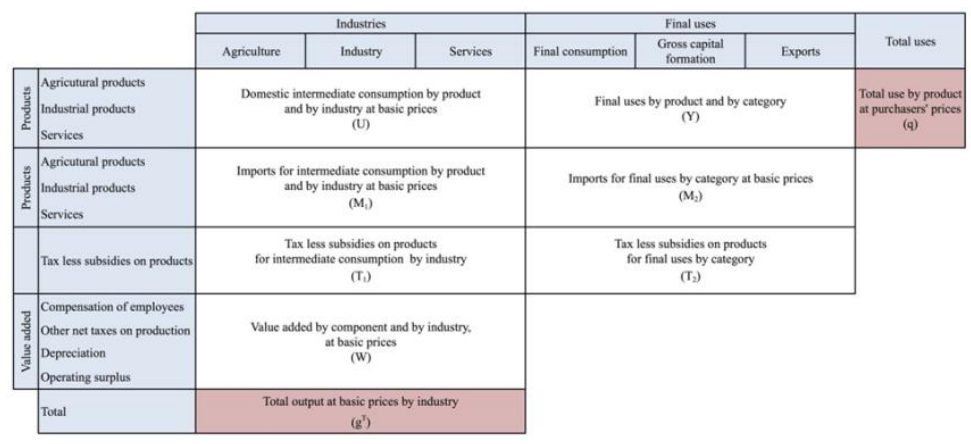

Figure 2. Layout of the use table

Source: Authors' adaptation from Eurostat (2008)

So we have a balance equation as:

$$
\mathrm{I}_{1} *\left(\mathrm{U}+\mathrm{M}_{1}\right)+\mathrm{T}_{1}+\mathrm{I}_{\mathrm{W}} * \mathrm{~W}=\mathrm{g}^{\mathrm{T}}
$$

where $I_{1}$ and $I_{W}$ are row vectors (\# of products and \# of value added categories, respectively).

Final uses matrix $Y$ shows final uses by category (columns) and by product (rows). The category of final uses includes: (1) Household consumption expenditure, (2) Government consumption expenditure, (3) Fixed capital formation, (4) Changes in inventories, and (5) Exports. So, we have column vector of total uses at purchasers' prices, $q$ (\# of product) as:

$$
\mathrm{U} * \mathrm{I}_{2}+\mathrm{Y} * \mathrm{I}_{\mathrm{Y}}=\mathrm{q}
$$

where $I_{2}$ and $I_{Y}$ is column vectors (\# of industry and \# of final uses categories, respectively).

\subsection{Prices in SUT: Purchasers' Prices vs. Producers' Prices}

Following Eurostat (2008) there are three ways in which goods and services may be valued they may be measured in the 2008 SNA, namely the basic prices, the producers' prices, and the purchasers' prices:

The relationship between different types of prices can be given as follows:

Producers' prices $=$ Basic prices + Taxes on products (excl. VAT) - Subsidies on products

Purchasers' prices $=$ Producers' prices + Trade $\&$ transport margins + Non-deductible VAT

For countries that collect value added data at purchasers' prices:

GDP at purchasers' prices = agriculture value added + industry value added + services value added at produces' prices

For countries that collect value added data at basic prices:

GDP at purchasers' prices $=$ agriculture value added + industry value added + services value added at basic prices + net taxes on products

\section{Compilation of SIOTs From SUTs}

This paper proposes mathematical techniques deriving the SIOTs from SUTs under the two technical assumptions, namely the industry technology assumption and the commodity technology assumption. In these proposed techniques, we use the matrix of input coefficients $B$ [\# of products by \# of industries], which would be derived from the use matrix as follows:

$$
\mathrm{B}=\mathrm{U} *(\operatorname{diag}(\mathrm{g}))^{-1}
$$

where:

$U$ : use matrix [\# of products by \# of industries]

$g$ : column vector of industry output [\# of industry]

$\operatorname{diag}(g)$ : diagonal matrix of industry output [\# of industry by \# of industry]. 


\subsection{The Industry Technology Assumption}

The industry technology assumption assumes that "each industry has its own specific way of production, irrespective of its product mix" (Eurostat, 2008, p.312). According to industry technology assumption, each industry has the same input requirements for any unit of output. In that case, the input structure of each product depends on what industry produces it.

Based on the industry technology assumption we could then define the matrix of make coefficients $D$ [\# industries by \# of products], as follows:

$$
\mathrm{D}=\mathrm{V} *(\operatorname{diag}(\mathrm{q}))^{-1}
$$

where:

$V$ : make matrix [\# of industry by \# of product]

$q$ : column vector of product output [\# of product]

$\operatorname{diag}(q)$ : diagonal matrix of product output [\# of product by \# of product].

From (4) (5) and (1) (6), respectively, we have:

$$
\begin{gathered}
B * g+y=q \\
D * q=g
\end{gathered}
$$

where $y$ is a column vector of final demand [\# of product].

Re-write equation (7) and (8) in the matrix form we have:

$$
\left(\begin{array}{ll}
0 & \mathrm{~B} \\
\mathrm{D} & 0
\end{array}\right) *\left(\begin{array}{l}
\mathrm{q} \\
\mathrm{g}
\end{array}\right)+\left(\begin{array}{l}
\mathrm{y} \\
0
\end{array}\right)=\left(\begin{array}{l}
\mathrm{q} \\
\mathrm{g}
\end{array}\right)
$$

The above relation returns to the standard Leontief relation:

$$
\left(\begin{array}{l}
\mathrm{q} \\
\mathrm{g}
\end{array}\right)=\left(\left(\begin{array}{ll}
\mathrm{I} & 0 \\
0 & \mathrm{I}
\end{array}\right)-\left(\begin{array}{ll}
0 & \mathrm{~B} \\
\mathrm{D} & 0
\end{array}\right)\right)^{-1} *\left(\begin{array}{l}
\mathrm{y} \\
0
\end{array}\right)
$$

Follow Miyazawa's partitioned matrix multipliers (1976, pp.60-62), equation (10) can be further elaborated with the help of the Schur-formula (Schur, 1917; Sonis and Hewings, 1993) as follows:

$$
\left(\begin{array}{l}
\mathrm{q} \\
\mathrm{g}
\end{array}\right)=\left(\begin{array}{cc}
\Delta_{1} & \Delta_{1} * \mathrm{~B} \\
\Delta_{2} * \mathrm{D} & \Delta_{2}
\end{array}\right) *\left(\begin{array}{l}
\mathrm{y} \\
0
\end{array}\right)
$$

with:

$$
\begin{aligned}
& \Delta_{1}=(\mathrm{I}-\mathrm{B} * \mathrm{D})^{-1} \\
& \Delta_{2}=(\mathrm{I}-\mathrm{D} * \mathrm{~B})^{-1}
\end{aligned}
$$

$\Delta_{1}$ and $\Delta_{2}$ are Leontief inverse matrices of input-output system with (product by product) and (industry by industry) corresponding. Hence, in the input-output system $(B * D)$ is direct input coefficient matrix $(A)$ that has dimension (\# of product by \# of product) and $(D * B)$ is direct input coefficient matrix $(A)$ that has dimension (\# of industry by \# of industry). Thus, from equation (12) and (13) we have:

$$
\begin{aligned}
A_{\text {product by product }} & =B_{\text {product by industry }} * D_{\text {industry by product }} \\
A_{\text {industry by industry }} & =D_{\text {industry by product }} * B_{\text {product by industry }}
\end{aligned}
$$

The equation (11) can be written as follow:

$$
\begin{gathered}
\mathrm{q}=(\mathrm{I}-\mathrm{B} * \mathrm{D})^{-1} * \mathrm{y} \\
\mathrm{g}=(\mathrm{I}-\mathrm{D} * \mathrm{~B})^{-1} *(\mathrm{D} * \mathrm{y})
\end{gathered}
$$

Equation (14) goes back the Leontief standard relationship. Equation (15) presents final demand for industries, which is a vector that is determined by $(D * y)$. 


\subsection{The Product Technology Assumption}

The product technology assumption assumes that "each product is produced in its own specific way, irrespective of the industry where it is produced" (Eurostat, 2008, p.311). According to product technology assumption, each industry produces only the total output of the product that is primary to that industry and that each product has its own input structure, irrespective of the industry that produces it.

Based on the product technology assumption we could define the coefficient matrix $C$ of supply table (\# of products by \# industries) as follows:

$$
\mathrm{C}=\mathrm{S} *(\operatorname{diag}(\mathrm{g}))^{-1}
$$

From (1) (16) and (4) (5), respectively, we have:

$$
\begin{gathered}
\mathrm{C}^{-1} * \mathrm{q}=\mathrm{g} \\
\mathrm{B} * \mathrm{~g}+\mathrm{y}=\mathrm{q}
\end{gathered}
$$

Where $B$ is the matrix of input coefficients (\# of products by \# of industries) as it was defined in equation (5).

Equations (17) and (18) could be rewritten in the matrix form as follows:

$$
\left(\begin{array}{cc}
0 & C^{-1} \\
B & 0
\end{array}\right) *\left(\begin{array}{l}
g \\
q
\end{array}\right)+\left(\begin{array}{l}
0 \\
y
\end{array}\right)=\left(\begin{array}{l}
g \\
q
\end{array}\right)
$$

Note that as $C$ is a \# of product by \# of industry matrix thus dimensions of $C^{-1}$ is \# of industry by \# of product.

Similar to what we have solved in equation (10), equation (19) would have the form as follows:

$$
\left(\begin{array}{l}
g \\
q
\end{array}\right)=\left(\begin{array}{cc}
\Delta_{1} & \Delta_{1} * C^{-1} \\
\Delta_{2} * B & \Delta_{2}
\end{array}\right) *\left(\begin{array}{l}
0 \\
y
\end{array}\right)
$$

In this case:

$$
\begin{aligned}
& \Delta_{1}=\left(\mathrm{I}-\mathrm{C}^{-1} * \mathrm{~B}\right)^{-1} \\
& \Delta_{2}=\left(\mathrm{I}-\mathrm{B} * \mathrm{C}^{-1}\right)^{-1}
\end{aligned}
$$

Implement equation (20), we have:

$$
\begin{gathered}
\mathrm{g}=\left(\mathrm{I}-\mathrm{C}^{-1} * \mathrm{~B}\right)^{-1} *\left(\mathrm{C}^{-1} * \mathrm{y}\right) \\
\mathrm{q}=\left(\mathrm{I}-\mathrm{B} * \mathrm{C}^{-1}\right)^{-1} * \mathrm{y}
\end{gathered}
$$

where $\left(C^{-1} * y\right)$ is final demand vector for industries.

In this assumption, the input-output coefficient $A$ is determined as follows:

\section{Empirical Study}

$$
\begin{aligned}
\mathrm{A}_{\text {industry by industry }} & =\mathrm{C}^{-1} \text { industry by product } * \mathrm{~B}_{\text {product by industry }} \\
\mathrm{A}_{\text {product by product }} & =\mathrm{B}_{\text {product by industry }} * \mathrm{C}^{-1} \text { industry by product }
\end{aligned}
$$

This section presents the empirical results of a compilation of SIOTs of Vietnam, using the SUTs of year 2007. The SUTs were aggregated for 3 sectors namely: (1) Agriculture, forestry and fisheries, (2) Exploiting, processing and constructing, and (3) Services.

\subsection{Industry Technology Assumption}

Under the industry technology assumption, the matrix of coefficients $B^{*}=\left(\begin{array}{cc}0 & B \\ D & 0\end{array}\right)$, is described in Table 1 .

Table 1. The matrix of coefficients $B^{*}$

\begin{tabular}{llllllll}
\hline & & \multicolumn{3}{c}{ PRODUCT } & \multicolumn{3}{l}{ INDUSTRY } \\
\cline { 2 - 7 } & & 1 & 2 & 3 & 1 & 2 & 3 \\
\hline PRODUCT & 1 & & & 0.20351 & 0.07418 & 0.01702 \\
\hline
\end{tabular}




\begin{tabular}{|c|c|c|c|c|c|c|c|}
\hline & \multicolumn{4}{|c|}{2} & 0.33595 & 0.54212 & 0.20670 \\
\hline & \multicolumn{4}{|c|}{3} & 0.06608 & 0.08495 & 0.17736 \\
\hline \multirow{3}{*}{ INDUSTRY } & 1 & 0.926 & 0.000 & 0.000 & & & \\
\hline & 2 & 0.000 & 0.660 & 0.001 & & & \\
\hline & 3 & 0.000 & 0.000 & 0.906 & & & \\
\hline Total & & 1 & 1 & 1 & 0.61 & 0.70 & 0.40 \\
\hline
\end{tabular}

Source: Authors' calculation from data of $\mathrm{ADB}^{1}$

Apply equation (11), the matrix $\left(I-B^{*}\right)^{-1}$ is shown in Table 2.

Table 2. $\left(\mathrm{I}-\mathrm{B}^{*}\right)^{-1}=\left(\begin{array}{cc}\Delta_{1} & \Delta_{1} * \mathrm{~B} \\ \Delta_{2} * \mathrm{D} & \Delta_{2}\end{array}\right)$

\begin{tabular}{|c|c|c|c|c|c|c|c|}
\hline & \multicolumn{3}{|c|}{ PRODUCT } & \multicolumn{3}{|c|}{ INDUSTRY } \\
\hline & & 1 & 2 & 3 & 1 & 2 & 3 \\
\hline \multirow{3}{*}{ PRODUCT } & 1 & 1.2744 & 0.1011 & 0.0462 & 0.2964 & 0.1533 & 0.0508 \\
\hline & 2 & 0.6571 & 1.6400 & 0.3794 & 0.7098 & 0.9700 & 0.4174 \\
\hline & 3 & 0.1368 & 0.1169 & 1.2203 & 0.1478 & 0.1772 & 0.2429 \\
\hline \multirow{3}{*}{ INDUSTRY } & 1 & 1.1799 & 0.0936 & 0.0428 & 1.2744 & 0.1419 & 0.0470 \\
\hline & 2 & 0.4337 & 1.0821 & 0.2517 & 0.4684 & 1.6402 & 0.2757 \\
\hline & 3 & 0.1240 & 0.1059 & 1.1059 & 0.1339 & 0.1606 & 1.2201 \\
\hline
\end{tabular}

Source: Authors' calculation from data of ADB

In this case, Leontief inverse matrices with dimension [\# of product by \# of product] and [\# of industry by \# of industry] are shown in Tables 3 and Table 4.

Table 3. Leontief inverse matrix [\# of product by \# of product]

\begin{tabular}{lllll}
\hline \multicolumn{5}{c}{ PRODUCT } \\
\hline \multirow{3}{*}{ PRODUCT } & \multicolumn{1}{c}{1} & 2 & 3 \\
& 1 & 1.2744 & 0.1011 & 0.0462 \\
\cline { 2 - 5 } & 2 & 0.6571 & 1.6400 & 0.3794 \\
\cline { 2 - 5 } & 3 & 0.1368 & 0.1169 & 1.2203 \\
\hline
\end{tabular}

Table 4. Leontief inverse matrix [\# of industry by \# of industry]

\begin{tabular}{|c|c|c|c|c|}
\hline \multicolumn{5}{|c|}{ INDUSTRY } \\
\hline & & 1 & 2 & 3 \\
\hline \multirow{3}{*}{ INDUSTRY } & 1 & 1.2744 & 0.1419 & 0.0470 \\
\hline & 2 & 0.4684 & 1.6402 & 0.2757 \\
\hline & 3 & 0.1339 & 0.1606 & 1.2201 \\
\hline
\end{tabular}




\subsection{Commodity Technology Assumption}

Regarding this assumption, coefficients of $B^{*}=\left(\begin{array}{cc}0 & C^{-1} \\ B & 0\end{array}\right)$ and $\left(I-B^{*}\right)^{-1}$ was shown in Table 5 and Table 6.

Table 5. The matrix of coefficients $B^{*}$

\begin{tabular}{|c|c|c|c|c|c|c|c|c|}
\hline & & \multicolumn{3}{|c|}{ INDUSTRY } & \multicolumn{3}{|c|}{ PRODUCT } & \multirow[t]{2}{*}{ Total } \\
\hline & & 1 & 2 & 3 & 1 & 2 & 3 & \\
\hline \multirow{3}{*}{ INDUSTRY } & 1 & & & & 1.00000 & 0.00000 & 0.00000 & 1 \\
\hline & 2 & & & & 0.00000 & 1.00050 & -0.00050 & 1 \\
\hline & 3 & & & & 0.00000 & 0.00000 & 1.00000 & 1 \\
\hline \multirow{3}{*}{ PRODUCT } & 1 & 0.204 & 0.074 & 0.017 & & & & \\
\hline & 2 & 0.336 & 0.542 & 0.207 & & & & \\
\hline & 3 & 0.066 & 0.085 & 0.177 & & & & \\
\hline
\end{tabular}

Source: Authors' calculation from data of ADB

Table 6. $\left(\mathrm{I}-\mathrm{B}^{*}\right)^{-1}=\left(\begin{array}{cc}\Delta_{1} & \Delta_{1} * \mathrm{C}^{-1} \\ \Delta_{2} * \mathrm{~B} & \Delta_{2}\end{array}\right)$

\begin{tabular}{llllllll}
\hline & & \multicolumn{5}{l}{ INDUSTRY } & \multicolumn{5}{l}{ PRODUCT } \\
\cline { 2 - 7 } & & 1 & 2 & 3 & 1 & 2 & 3 \\
\hline \multirow{3}{*}{ INDUSTRY } & 1 & 1.3629 & 0.2372 & 0.0878 & 1.3629 & 0.2373 & 0.0877 \\
\cline { 2 - 8 } & 2 & 1.1017 & 2.4837 & 0.6469 & 1.1017 & 2.4850 & 0.6456 \\
\cline { 2 - 8 } PRODUCT & 3 & 0.2232 & 0.2755 & 1.2894 & 0.2232 & 0.2757 & 1.2893 \\
& 1 & 0.3629 & 0.2372 & 0.0878 & 1.3629 & 0.2373 & 0.0877 \\
\hline & 2 & 1.1013 & 1.4831 & 0.6467 & 1.1013 & 2.4839 & 0.6460 \\
\hline
\end{tabular}

Source: Authors' calculation from data of ADB

In this case, Leontief inverse matrices with dimension [\# of product by \# of product] and [\# of industry by \# of industry] were shown in Table 7 and Table 8.

Table 7. Leontief inverse matrix [\# of product by \# of product]

\begin{tabular}{lllll}
\hline & \multicolumn{3}{l}{ PRODUCT } & \\
\cline { 2 - 4 } & & 1 & 2 & 3 \\
\hline \multirow{3}{*}{ PRODUCT } & 1 & 1.3629 & 0.2373 & 0.0877 \\
\cline { 2 - 5 } & 2 & 1.1013 & 2.4839 & 0.6460 \\
\cline { 2 - 5 } & 3 & 0.2232 & 0.2757 & 1.2893 \\
\hline
\end{tabular}


Table 8. Leontief inverse matrix [\# of industry by \# of industry]

\begin{tabular}{lllll}
\hline & \multicolumn{4}{l}{ INDUSTRY } \\
\hline \multirow{3}{*}{ INDUSTRY } & 1 & 1 & 2 & 3 \\
\hline & 2 & 1.3629 & 0.2372 & 0.0878 \\
\cline { 2 - 5 } & 3 & 1.1017 & 2.4837 & 0.6469 \\
\hline
\end{tabular}

Finally, Table 9 shows backward linkages and forward linkages with two types of consumptions.

Table 9. Backward linkages (BL) and forward linkages (FL) with two consumptions

\begin{tabular}{lllllllll}
\hline \multirow{2}{*}{$\begin{array}{l}\text { Sec-t } \\
\text { ors }\end{array}$} & \multicolumn{2}{l}{ Industry technology assumption } & \multicolumn{5}{l}{ Commodity technology assumption } \\
\cline { 2 - 9 } & Product by product & \multicolumn{2}{l}{ Industry by industry } & \multicolumn{2}{l}{ Product by product } & \multicolumn{2}{l}{ Industry by industry } \\
\cline { 2 - 9 } & BL & FL & BL & FL & BL & FL & BL & FL \\
\hline $\mathbf{1}$ & 2.686 & 1.687 & 2.685 & 1.687 & 2.687 & 1.688 & 2.688 & 1.688 \\
\hline $\mathbf{2}$ & 2.992 & 4.227 & 2.993 & 4.226 & 2.997 & 4.231 & 2.996 & 4.232 \\
\hline $\mathbf{3}$ & 2.024 & 1.788 & 2.023 & 1.788 & 2.023 & 1.788 & 2.024 & 1.788 \\
\hline
\end{tabular}

Source: Authors' calculation from data of ADB

\section{Conclusion and Discussion}

Currently, some countries publish SUTs and some countries publish both of SUTs and IOT, so, the applied matrix approach proposed by this paper will make it easier to convert from SUTs to SIOTs.

There are two assumptions about the relationship between the SUTs and the SIOTs. The product technology assumption is better on economic significance since primary and secondary products were produced by different technologies, but it does meet an obstacle, that appears negative numbers in intermediate input matrix of input-output system. In case, the RAS method was used to balancing again between gross output and gross input.

In case that the supply and use matrices are un-square, the product technology assumption cannot apply. Only the industry technology assumption could be applied for converting from SUTs to SIOTs, but this leads to another more difficult problem to accept that several products have identical coefficients. Therefore, for countries applying both input-output analysis and CGE model, when compiling SUTs, they should choose the number of commodities equal to the number of industries (so that the make and use matrixes are square).

The intermediate input matrices compiled under the two assumptions are different, and can also different vis-à-vis that resulted from conducting a direct survey for compiling the IOT. The difference more or less is due to the relevance of the make matrix. If the elements outside the diagonal of the make matrix differ too far from the primary products on the diagonal, the intermediate input matrix of SIOTs will deviate from the reality of the economy.

1993 and 2008 SNA revisions recommend that elements of the supply matrix should be at basic prices and elements of the use matrix should be at purchasers' price. Thus, to convert SUTs to SIOTs, the prices of the supply matrix and use matrix should be at the same prices.

Are the SUTs in 1993 and 2008 SNA revisions only for serving CGE models, ignoring input-output analysis? Is this a plot to overshadow the merits of Leontief?

\section{References}

Bui, T. (2016). A study on the Input-Output System for evaluation of infrastructure development in Vietnam. Kyoto: Kyoto University Press.

Bui, T., Kobayashi, K., \& Kim, K. M. (2012). The supply and use tables: the approach for conversion to input-output table. Advances in Management \& Applied Economics, 2(2), 83-89. 
Eurostat. (2008). Eurostat manual of supply, use and input-output tables, Methodologies and working papers. Luxembourg: Office for Official Publications of the European Communities.

Guo, J., Lawson, A. M., \& Planting, M. A. (2002). From make-use to symmetric i-o tables: an assessment of alternative technology assumptions. WP2002-03, October.

Jansen, P., \& Ten Raa, T. (1990). The choice of model in the construction of input-output coefficients matrices. International Economic Review, 31(1), 213-227. https://doi.org/10.2307/2526639

Miyazawa, K. (1976). Input-output analysis and the structure of income distribution. In M. Beckmann, \& H. P. Künzi (Eds.), Lecture notes in economics and mathematical system (p. 116). Berlin: Springer-Verlag.

Schur, I. (1917). Uber Potenzreichen, die im Inn em des Einhcitskreiscsbeschranktsind. Journal Für Die Reine Und Angewandte Mathematik, 147, 205-232.

Soklis, G. (2009). The conversion of the supply and use tables to symmetric input-output tables: a critical review. Bulletin of Political Economy, 3(1), 51-70.

Sonis, M., \& Hewings. G. J. D. (1993). Hierarchies of regional sub-structures and their multipliers within input-output systems: miyazawa revisited. Hitotsubashi Journal of Economics, 34(1), 33-44. https://doi.org/10.15057/7798

United Nations. (1968). A system of national accounts. New York: United Nations.

United Nations. (1999). Handbook of input-output table compilation and analysis, Studies in Methods, Handbook of National Accounts. New York: United Nations. Retrieved from https://unstats.un.org/unsd/publication/SeriesF/SeriesF_74E.pdf

United Nations. (2009). System of national accounts 2008. New York: European Commission, International Monetary Fund, Organization for Economic Co-operation and Development, United Nations and World Bank. Retrieved from https://unstats.un.org/unsd/nationalaccount/docs/SNA2008.pdf

\section{Note}

Note 1. The last IOT of Vietnam is in 2012, but the General Statistics Office of Vietnam did not publish supply and use table in 2012. Hence, in this paper, supply and use tables of 2007 were used for compilation of SIOTs from SUTs.

\section{Copyrights}

Copyright for this article is retained by the author(s), with first publication rights granted to the journal.

This is an open-access article distributed under the terms and conditions of the Creative Commons Attribution license (http://creativecommons.org/licenses/by/4.0/). 